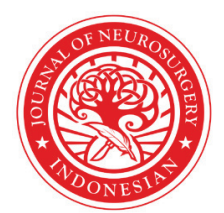

\title{
The efficacy of magnesium sulfate administration in diffuse axonal injury cases
}

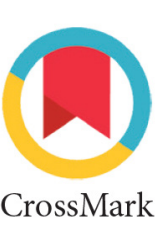

\author{
Yoki Oktadi Putra1* , Syaiful Saanin ${ }^{2}$, Hesty Lidya Ningsih²
}

\section{ABSTRACT}

Introduction: Diffuse axonal injury is a type of severe head injury. In overall head injury cases, it is estimated that $60 \%$ of severe head injuries and $40 \%$ of head injury cases were associated with diffuse axonal injury. Diffuse axonal injury is found in secondary brain injury with the occurrence of an ischemic brain. Magnesium sulfate plays a role as a deciphering agent in severe head injury and ischemic brains. This study was conducted to investigate the efficacy of magnesium sulfate administration in patients with diffuse axonal injury.

Methods: This research was conducted using a quasi-experimental design for three months, from 0ctober to December 2019, involving patients with severe head injury admitted to the emergency room of Dr. M. Djamil General Hospital, Padang.

Results: The results showed that magnesium sulfate administration was more effective than conventional therapy in improving the level of consciousness of patients with severe head injuries, but there was no significant difference between the two groups ( $p>$ 0.05). The number of patients was equally analyzed between the two study groups using independent t-test analysis on SPSS.

Conclusion: Magnesium sulfate administration was more effective than conventional therapy, but the difference was not statistically significant. Age and onset must be considered by researchers to assess the performance of magnesium sulfate therapy in diffuse axonal injury patients.

Keywords: diffuse axonal injury, magnesium sulfate, severe head injury

Cite This Article: Putra, Y.0., Saanin, S., Ningsih, H.L. 2020. The efficacy of magnesium sulfate administration in diffuse axonal injury cases. Indonesian Journal of Neurosurgery 3(1): 29-32. D0I: 10.15562/ijn.v3i1.104

'Department of Surgery, Faculty of Medicine, Universitas Andalas, Dr. M. Djamil General Hospital, Padang, Indonesia. 2Department of Neurosurgery, Faculty of Medicine, Universitas Andalas, Dr. M. Djamil General Hospital, Padang, Indonesia.

*Corresponding author: Yoki Oktadi Putra; Department of Surgery, Faculty of Medicine, Universitas Andalas, Dr. M. Djamil General Hospital, Padang, Indonesia;

yokioktadiputra86@gmail.com

Received: 2020-02-09

Accepted: 020-02-21

Published: 2020-04-09

\section{INTRODUCTION}

Diffuse axonal injury (DAI) is a traumatic brain injury due to blunt force injury on the head. DAI is a leading cause of death and disability, affecting children to young adults. ${ }^{1,2}$ Brain injuries are classified into mild, moderate, and severe based on the Glasgow Coma Scale (GCS). GCS classifies traumatic brain injury as mild (GCS of 13-15), moderate (GCS of 9-12), and severe $(\mathrm{GCS}<8)$. ${ }^{3,4}$

DAI mostly affects the white matter tract in the brain. The clinical condition of the patient with DAI may vary from normal, neurological deficits, to a comatose state. However, patients with DAI generally have severe clinical conditions. The most frequent etiology of DAI is high-speed motor vehicle accidents. The most common mechanism is due to acceleration-deceleration leading to a shift in power in the white matter tract of the brain. This causes microscopic damage to the axons at the border of the white and gray matter. ${ }^{5}$ DAI usually affects the white matter involved in the corpus callosum and brain stem, and there is no relationship between diffuse axonal brain injury and underlying skull fractures.

A large number of patients with severe traumatic injuries without mass lesions, such as Epidural Hematoma (EDH) or Subdural Hematoma (SDH), and a GCS less than 8 are more likely to experience DAI. ${ }^{3}$ DAI is a reflection of how severe the brain injury is. Patients with DAI have very minimal improvement, in contrast to $\mathrm{EDH}$ or $\mathrm{SDH}$, and significant improvement in neurological function can be evaluated after hematoma evacuation. DAI leads to termination or damage among neuron connection and affects many functional areas of the brain. Patients with DAI during the examination will show bilateral neurological deficits and often affect the white matter of the frontal and temporal lobes, the corpus callosum, and the brain stem.

Magnesium as a neuroprotector is approved by many preclinical ischemic and excitotoxic brain injury models. Even in severe head injuries, magnesium administration is believed to improve patient outcomes. Some possible mechanism of magnesium as a neuroprotector include regulating cellular energy metabolism, vascular tone, and ion transport in cell membranes. Magnesium is commonly used as a calcium antagonist in plasma. Magnesium causes vasodilatation by stimulating endothelial prostacyclin release while preventing vasoconstriction. ${ }^{3}$ 
Early ischemia is characterized by a focal reduction in cerebral blood flow of $<18 \mathrm{~mL} / 100 \mathrm{~g} /$ min, which leads to poor blood supply and ischemic necrosis. Health and Vink have shown a significant decrease in free $\mathrm{Mg}++$ concentration in the brain after traumatic brain injury (TBI); this correlates with neurological deficits and prognosis. Research from Sun Yat-Sen Hospital in China demonstrated that the administration of magnesium sulfate 20 minutes after a head injury is an effective treatment for focal or diffuse TBI. Magnesium sulfate administration improved neurological outcomes compared to placebo. Therefore, researchers believed this provides high clinical value to further investigate the impact of early and ongoing magnesium administration on TBI. ${ }^{1,2}$ This study aimed to evaluate the clinical effects of magnesium sulfate in the treatment of DAI.

\section{METHODS}

This study was a quasi-experimental design conducted from October to December 2019 in the semi-intensive care department of the Dr. M. Djamil General Hospital, Padang. The participants of this study were severe head injury patients with a GCS of $<8$, with or without lesions, admitted in the surgical department of Dr. M. Djamil General Hospital, Padang between October and December 2019. Data collected were analyzed using univariate analysis, and the numerical t-test analysis was used

Table 1. Patient characteristics based on the age group

\begin{tabular}{rcccc}
\hline Age Group & Control & F & Case & f \\
\hline $\mathbf{1 8 - 2 9}$ years & 12 & $66 \%$ & 11 & $61 \%$ \\
$\mathbf{3 0 - 4 0}$ years & 6 & $33 \%$ & 7 & $38 \%$ \\
\hline
\end{tabular}

Table 2. Patient characteristics based on onset

\begin{tabular}{|c|c|c|c|c|}
\hline Onset & Control & f & Case & $\mathbf{F}$ \\
\hline$<10$ hours & 11 & $61 \%$ & 13 & $72 \%$ \\
\hline$>10$ hours & 7 & $38 \%$ & 5 & $27 \%$ \\
\hline
\end{tabular}

Table 3. Patient characteristics based on average therapy outcome

\begin{tabular}{lcc}
\hline \multicolumn{1}{c}{ Therapy } & Baseline GCS & Subsequent GCS \\
\hline $\mathrm{MgSO}_{4}$ & 7.5 & 9.3 \\
Conventional & 6.7 & 8.1 \\
\hline
\end{tabular}

Table 4. Difference in the average outcome of conventional therapy and $\mathrm{MgSO}_{4}$

\begin{tabular}{|c|c|c|}
\hline Therapy & $X \pm S D$ & $\mathbf{p}$ \\
\hline $\mathrm{MgSO} 4$ & 1.38890 .6 & \multirow{2}{*}{0.175} \\
\hline Conventional & $\begin{array}{lll}1.6667 & 0.48\end{array}$ & \\
\hline
\end{tabular}

to compare the average of the two case groups.

The magnesium sulfate (MST) group was given $250 \mu \mathrm{mol} / \mathrm{kg}$ of magnesium sulfate $\left(\mathrm{MgSO}_{4}\right)$ intravenously 20 minutes after admission, followed by $750 \mu \mathrm{mol} / \mathrm{kg}$ of intravenous $\mathrm{MgSO}_{4}$ every day for three days. The control group received standard management without $\mathrm{MgSO}_{4} \cdot{ }^{6}$ Result data were collected three days after conventional and magnesium sulfate therapy.

\section{RESULTS}

The results were analyzed based on the GCS followup data of severe head injury patients who were treated in the semi-intensive ward of the Dr. M. Djamil General Hospital, Padang between October and December 2019. A quasi-experimental design was conducted involving 36 samples that were divided into two groups, namely a severe head injury group receiving conventional therapy (control group) and the other group receiving $\mathrm{MgSO}_{4}$ therapy (MST group), each consisting of 18 people.

Table 1 shows that DAI patients were mostly in the age group of $18-29$ years old; in this age group, as many as $11(61 \%)$ patients were given MST treatment and 12 (66\%) patients in the control group.

Based on the onset of events (Table 2), this study shows that 11 patients $(61 \%)$ in the control group and 13 patients (72\%) in the MST group had an accident $<10$ hours before being admitted to the hospital. In this study, there are still differences in the onset of patient admission to Dr. M. Djamil General Hospital, Padang, which is partly due to geographical factors and the transportation available in the patient referral process. On the other hand, in the study by Zhao Ling et al., ${ }^{1}$ all patients were admitted to the hospital within $<1$ hour after the accident.

The therapy outcome of both groups is presented in Table 3. The case group received $\mathrm{MgSO}_{4}$ therapy had more improvement in the level of consciousness.

From Table 4, it was found that $\mathrm{MgSO}_{4}$ therapy was more effective in improving the level of consciousness of patients with severe head injuries, but there was no significant difference between the two types of therapy $(\mathrm{p}>0.05)$.

\section{DISCUSSION}

Approximately $50 \%$ of patients with accelerationdeceleration trauma were diagnosed with diffuse axonal injury (DAI). ${ }^{7}$ Clinically, DAI is characterized by the loss of consciousness after an accident, low GCS, and abnormal findings on CT scans seen mainly from bleeding or petechiae in 
cortico-subcortical area, splenium of the corpus callosum, basal ganglia and brain stem. ${ }^{7,8}$ The initial damage to axons is demonstrated by the presence of massive eosinophilia and argyrophilic accumulation in the nerve fibers, as known as axonal retraction balls. ${ }^{9}, 10$ Microscopically, lesions on DAI are usually ovoid or elliptical, following the long axis of the affected axon. ${ }^{11}$ Their distribution is not uniform or symmetrical, occurring mainly in the grey-white matter junction, corpus callosum, septum, fornix, internal capsule, tegmentum, and cerebellar dorsal folia to the dentate nucleus. ${ }^{12,13}$ Lesions are often followed with bleeding, which occurs in a linear pattern, following layer distortion. At a later stage, atrophy dominates the features. Cholinergic neurons are more susceptible than other neurotransmitter categories. Immunocytochemical staining for b-amyloid (b-APP) precursor protein detects large sensitivity in axons with DAI. ${ }^{14}$

CT scan is the most commonly used imaging modality in the emergency setting of head trauma. Most brain CT scan findings are capable of producing a correct diagnosis. ${ }^{15} \mathrm{MRI}$ is the best imaging modality in confirming the diagnosis and classifying lesions, using the Gennarelli rating scale. This scale classified the findings into three groups: lesions with and without bleeding in the graywhite matter especially in the temporal and frontal regions (type 1), combined lesions in and around corpus callosum (type 2), and with lesions in basal ganglia and brain stem (type 3). ${ }^{16,17}$

DAI is diagnosed according to the definition of Adams and Gennarelli. Normal tomographic findings, small or collapse ventricles, subarachnoid
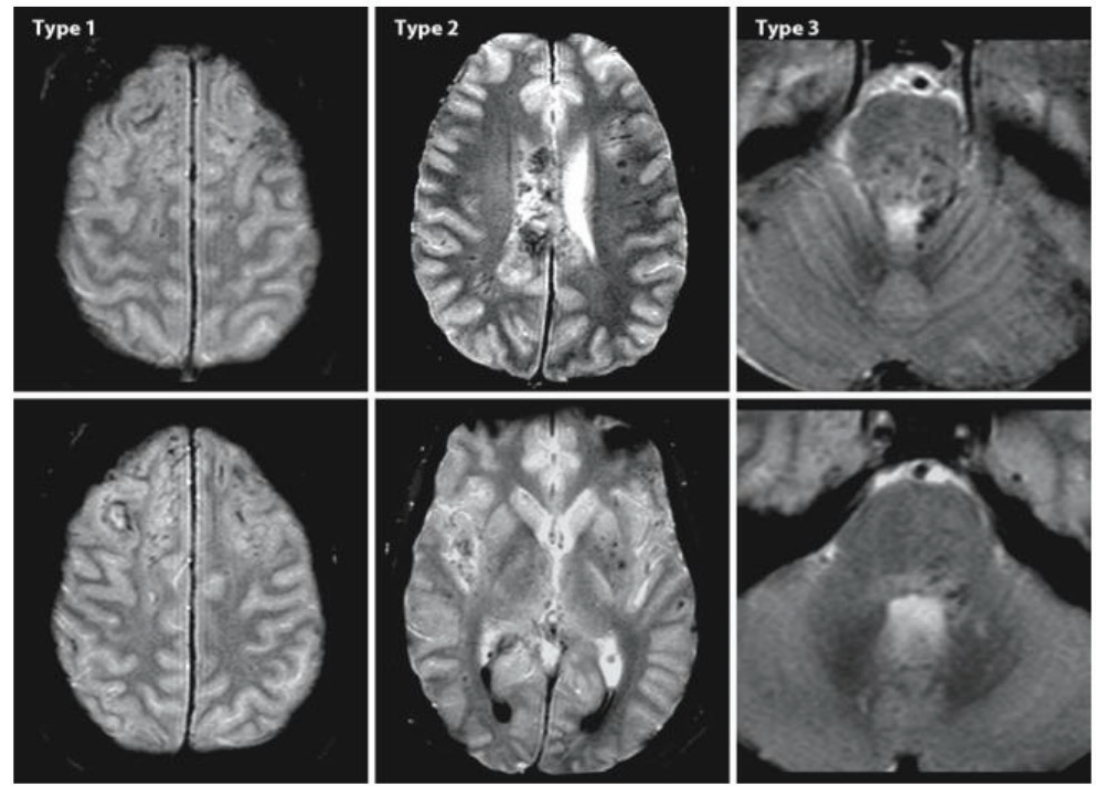

hemorrhage, intraventricular hemorrhage, or small hematoma in white matter with or without midline shift $<5 \mathrm{~mm}$, or in combination, and a scale score (GCS) $<8$ during admission. ${ }^{18}$

The patient was immediately intubated if there are any signs of respiratory distress observed, GCS score $<6$, or if there are any poor airway reflexes. Intravenous line and central venous catheter placement needed to be performed. Mechanical ventilation was adjusted to maintain partial pressure of carbon dioxide in arterial blood between 32 and $35 \mathrm{mmHg}$. Patients were assessed neurologically by the nursing staff every hour (more often if there is any worsening of the condition). Hyperventilation, mannitol, and cerebral spinal fluid drainage are only performed if the patient shows signs of increased intracranial pressure. $^{19}$

This study was conducted in 36 severe head injuries patient with a GCS of $<8$ who were diagnosed with DAI based on physical examination and brain CT scan findings, admitted to Dr. M. Djamil General Hospital, Padang from October to December 2019. Patients were classified into 2 treatment groups, namely conventional therapy and $\mathrm{MgSO}_{4}$ therapy group. Each group was assessed according to GCS changes for 3 days in a semiintensive room of the surgical department of Dr. M. Djamil General Hospital, Padang. An average increase of GCS was $1-2$ points from baseline. There were no significant differences between the two groups. However, $\mathrm{MgSO}_{4}$ administration was superior to conventional therapy. A similar study was conducted by Zhao Ling et al. at Sun Yat-Sen Hospital in China involving severe head injury patients with a GCS of $<8$, with statistically significant analysis results $(\mathrm{p}=0.004)$. Research at Sun Yat-Sen Hospital in China showed that there was a significant positive correlation between GCS and $\mathrm{MgSO}_{4}$ administration for DAI patients.

In the present study, there was no significant difference $(\mathrm{p}>0.05)$ between patients with conventional therapy and $\mathrm{MgSO}_{4}$ therapy. For the characteristics based on the age group, the highest incidence occurred in the $18-29$ years age group in both the case and control group $(61 \%$ and $66 \%$, respectively). Based on the onset, the $<10$-hour group showed a higher incidence in both the case and control groups (61\% and $72 \%$, respectively). Regarding the comparison between baseline GCS and subsequent GCS after therapy administration, $\mathrm{MgSO}_{4}$ administration increased the mean baseline GCS of 7.5 to 9.3 , while conventional therapy only increased the mean baseline GCS of 6.7 to 8.1. Factors influencing the efficacy of $\mathrm{MgSO}_{4}$ administration were the patient's age and the onset of trauma.

Figure 1. MRI findings in DAI

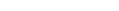




\section{CONCLUSION}

In this study, $\mathrm{MgSO}_{4}$ administration was more effective than conventional therapy, but there was no statistically significant difference $(\mathrm{p}>0.005)$. Age, risk factors, onset, and other concurrent trauma were considered by the clinician to assess the performance of $\mathrm{MgSO}_{4}$ therapy in DAI patients in the semi-intensive ward of the surgical department of Dr. M. Djamil General Hospital, Padang. The study was conducted in accordance with the $\mathrm{MgSO}_{4}$ protocol; the MST group was administered 250 $\mu \mathrm{mol} / \mathrm{kg}$ of magnesium sulfate intravenously 20 minutes after admission, followed by $750 \mu \mathrm{mol} / \mathrm{kg}$ of intravenous magnesium sulfate daily for 3 days. Before the therapy was administered, researchers explained and provide informed consent in advance to the patient's family.

\section{ACKNOWLEDGMENTS}

Thank you to all of those who have helped in conducting this study, in particular to the chief director of Dr. M. Djamil General Hospital, Padang who permitted this research to be conducted and to the semi-intensive surgical department ward who helped the author to carry out this research.

\section{FUNDING}

There is no funding

\section{CONFLICT OF INTEREST}

There is no conflict of interest

\section{ETHICAL APPROVAL}

There is no ethical approval

\section{AUTHORS' CONTRIBUTIONS}

The first author did the literature review and wrote the manuscript. The second and third authors provided further ideas and advice for correction.

\section{REFERENCES}

1. Zhao L, Wang W, Zhong J, Li Y, Cheng Y, Su Z, Zheng W, Guan XD. The effects of magnesium sulfate therapy after severe diffuse axonal injury. Ther Clin Risk Manag. 2016; 12: 1481-1486. DOI: 10.2147/TCRM.S109482.

2. Davies, DJ. Supplementary Magnesium in Traumatic Brain Injury: where do we go from here?". J R Army Med Corps. 2018; 164(6): 397-398. DOI: 10.1136/jramc-2018-000985.

3. Smith DH, Meaney DF, Shull WH. Diffuse Axonal Injury in Head Trauma. J Head Trauma Rehabil. 2003; 18(4): 307-16. DOI: 10.1097/00001199-200307000-00003.

4. Dhandapani SS, Gupta A, Vivekanandhan S, Sharma BS, Mahapatra AK. A randomized controlled trial of magnesium sulfate in severe closed traumatic brain injury. IJNT. 2008; 5(1): 27-33. DOI: 10.1016/s0973-
0508(08)80025-1

5. Vink R, Cook NL, Van den Heuvel C. Magnesium in acute and chronic brain injury; an update. Magnesium Research. 2009; 22(3): 158S-62S. DOI: 10.1684/mrh.2009.0175.

6. Smith DH, Hicks R, Povlishock JT. Therapy development for diffuse axonal injury. J Neurotrauma. 2013; 30(5): 307 23. DOI: $10.1089 /$ neu.2012.2825.

7. Takaoka M, Tabuse H, Kamura E, Nakajima S, Tsuzuki T, Nakamura K, Okada A, Sugimoto H. Diffuse Axonal Injury. In: Magnetic Resonance of Myelination and Myelin Disorders. Berlin: Springer; 2005. p. 823-831.

8. Li W, Bai YA, Li YJ, Liu KG, Wang MD, Xu GZ, Shang HL, Li YF. Magnesium Sulfate for Acute Traumatic Brain Injury. J Craniofac Surg. 2015; 26(2): 393-8. DOI: 10.1097/ SCS.0000000000001339.

9. Sen AP, Gulati A. Use of Magnesium in Traumatic Brain Injury. Neurotherapeutics. 2010; 7(1): 91-9. DOI: 10.1016/j. nurt.2009.10.014

10. IOM (Institute of Medicine). Erdman J, Oria M, Pillsbury L. Nutrition and Traumatic Brain Injury: Improving Acute and Subacute Health Outcomes in Military Personnel. Washington, DC: The National Academies Press; 2011.

11. Heath DL, Vink R. Neuroprotective Effects of $\mathrm{MgSO} 4$ and $\mathrm{MgCl} 2$ in Closed Head Injury: A Comparative Phosphorus NMR Study. J Neurotrauma. 1998; 15(3): 183-9. DOI: 10.1089/neu.1998.15.183.

12. Temkin NR, Anderson GD, Winn HR, Ellenbogen RG, Britz GW, Schuster J, Lucas T, Newell DW, Mansfield PN, Machamer JE, Barber J. Magnesium sulfate for neuroprotection after traumatic brain injury: a randomized controlled trial. Lancet Neurology. 2007; 6(1): 29-38. DOI: 10.1016/S1474-4422(06)70630-5.

13. Jain KK. Neuroprotection in Traumatic Brain Injury. In: The Handbook of Neuroprotection. New York: Humana; 2019. p. 281-336.

14. Esen F, Erdem T, Aktan D, Kalayci R, Cakar N, Kaya M, Telci L. Effects of Magnesium Administration on Brain Edema and Blood-Brain Barrier Breakdown After Experimental Traumatic Brain Injury in Rats. J Neurosurg Anesthesiol. 2003; 15(2): 119-25. DOI: 10.1097/00008506200304000-00009.

15. Inglese $\mathrm{M}$, Makani S, Johnson G, Cohen BA, Silver JA, Gonen O, Grossman RI. Diffuse axonal injury in mild traumatic brain injury: a diffusion tensor imaging study. J Neurosurg. 2005;103(2): 298-303. DOI: 10.3171/ jns.2005.103.2.0298.

16. Humble SS, Wilson LD, Wang L, Long DA, Smith MA, Siktberg JC, Mirhoseini MF, Bhatia A, Pruthi S, Day MA, Muehlschlegel S. Prognosis of diffuse axonal injury with traumatic brain injury. J Trauma Acute Care Surg. 2018; 85(1): 155-159. DOI: 10.1097/TA.0000000000001852.

17. Mittal P. Diffuse axonal injury: pathological and clinical aspects. Forensic Res Criminol Int J. 2015; 1(4): 157-160. DOI: 10.15406/frcij.2015.01.00026.

18. Adams JH, Doyle D, Ford I, Gennarelli TA, Graham DI, Mclellan DR. Diffuse axonal injury in head injury: Definition, diagnosis, and grading. Histopathology. 1989;15: 49-59. DOI: 10.1111/j.1365-2559.1989.tb03040.x.

19. Hammoud DA, Wasserman BA. Diffuse axonal injuries: pathophysiology and imaging. Neuroimaging Clin N Am. 2002; 12(2): 205-16. DOI: 10.1016/s10525149(02)00011-4.

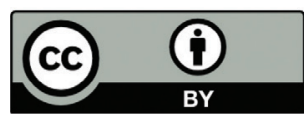

This work is licensed under a Creative Commons Attribution 